\title{
VIDAL (BEN) SAÚL SATORRE, COPISTA HEBREO (1383-1411) *
}

ASUNCIÓN BLASCO MARTÍNEZ

Universidad de Zargoza

DAVID ROMANO

Universidad de Barcelona

\section{SUMARIO}

0. Introdución

1. Planteo del problema

2. Vidal Satorre o Vidal Saúl en Lérida y Cervera (1353 y 1385)

3. Vidal Saúl Satorre en Zaragoza (1389-1411)

\section{INTRODUCCIÓN}

El 5 de diciembre de 1989 Sotheby's vendió en pública subasta una Biblia manuscrita en hebreo, con miniaturas. Este manuscrito, que perteneciera a la colección Sassoon, suele conocerse con la denominación de Biblia de Rašbá porque fue escrita para n'Astruc ${ }^{1}$ b. R. Ișhaq b. R. Šlomó b. Adret: el acrónimo hebreo de este R. Šlomó b. Adret sería Rašbá (nombre que designa al célebre rabino barcelonés) ${ }^{2}$.

No vamos a entrar aquí ni en el valor del texto ni en la calidad de las miniaturas. Tan sólo nos ocuparemos de la personalidad del copista.

- En la realización de este trabajo nos hemos beneficiado parcialmente de la ayuda del proyecto $\mathrm{n}^{2}$ PB87-0011-C02-00 de la Dirección General de Investigación Científica y Técnica (DGICYT) del Ministerio de Educación y Ciencia. Agradecemos al prof. Manuel Mundó que nos haya proporcionado la noticia de la subasta y algún dato documental cervariense.

1 No "Ibn Astruc" como dice el folleto de Sotheby's.

2 Hay dos personajes coetáneos casi homónimos: Š̌lomó ben Adret y Š̌̌lomó Adret según puede apreciarse en un pergamino de la época. Véase la reproducción de las dos firmas en D. Romano, La signature de $R$. Shelomoh ben Adret (RaShBA) de Barcelone, en «Les juifs au regard de l'histoire. Mélanges en l'honneur de Bernhard Blumenkranz», Paris 1985, pág. 197. 


\section{Planteo del problema}

El folleto de la subasta decía que el manuscrito se acabó de copiar en Cervera en el mes de 'elûl de 5143, que correspondería al período 31.7 a 29.8.1383, y que el copista fue «Vidal ben Shaul Sartori [Stori]". El catálogo de Sassoon, más cauto, copió el colofón hebreo y en caracteres latinos escribió: «Scribe: Vidal b. Shaul 'סטר", es decir, que no tradujo el "apellido" 3.

No parece que el topónimo Cervera plantee dificultad, pues aunque existen en la Península Ibérica otros Cervera (por ejemplo, Cervera de Río Alhama, Cervera de Pisuerga, etc.) son mucho menos importantes que el Cervera catalán con el que sin vacilar lo identifica el folleto de Sotheby's (añadiendo detalles históricos, básicamente tomados de Baer).

En cuanto al nombre del escriba, las interpretaciones señalan las grafias Sartori ${ }^{4}$, Stori y Satori ${ }^{5}$. Estas grafias nos llamaron de inmediato la atención por dos motivos: 1) porque no son formas ni catalanas ni hebreas, y 2) porque, en cambio, imaginando -en un primer momento no teníamos a disposición el texto del colofónun hebreo סטורי inmediatamente cabía la posibilidad de una lectura en romance catalán Satorre. Es decir, que nos hallaríamos ante un Vidal ben Saúl Satorre, quizás sólo Vidal ben Saúl o Vidal Satorre. $Y$, en efecto, esta grafía hebrea es la que figura en el catálogo de manuscritos de Sassoon ${ }^{6}$.

Un segundo punto surgió algo más tarde. El folleto añadía que "Another manuscript by the present scribe was written in 1404" y, en efecto, el catálogo de Sassoon especifica que este manuscrito חיים ברי שאול מגדולי זיול חido המכונה וידאל סטורי Aunque Beit-Arié y Sirat sigan escribiendo Vidal

\footnotetext{
${ }^{3}$ La estructura de los nombres de los judíos de Lérida vacila entre la tradición catalana de usar el patronímico y la tradición aragonesa (e hispánica en general) de valerse de apellido.

4 Así A. Freimann, Kopisten hebräischer Handschriften in Spanien und Portugal, *Zeitschrift für hebräische Bibliographie» XIV (1910) pág. 107, n 16.

s Esta última figura en el catálogo de M. BEIT-ARIÉ y C. SIRAT, Manuscrits médievaux en caractères hébraiques portant des indications de date jusqu'd 1540, Paris 1980, II, 45.

6 Ohel David. Descriptive Catalogue of the Hebrew and Samaritan Manuscripts in the Sassoon Library, vol. I, London 1932, págs. 14-15, n² 16.
} 
Satori ${ }^{7}$, el texto hebreo transcrito corrobora la igualdad Satorre $=$ Migdolí, lógica puesto que se trata del mismo apellido escrito una vez en catalán y otra en hebreo.

\section{Vidal Satorre o Vidal SaÚl en Lérida y Cervera (1353 y 1385)}

Todavía no se ha escrito la historia de los judíos de Cervera. Aunque esa historia no haya sido estudiada en profundidad, algunos documentos han sido dados a conocer por Durán y Sanpere 8, Baer ${ }^{9} \mathrm{y}$ otros autores ${ }^{10}$. Una ojeada a todos ellos sólo ha brindado unos pocos datos aislados y sin especial significación para nuestro objeto. En otras palabras: habrá que esperar a que se haga una investigación en los fondos del Archivo Histórico Comarcal de Cervera. Pero, entre tanto, quizás no sea inútil exponer los datos hallados.

En 1353 un "Vitalis ça Torre» fue uno de los muchos judíos ilerdenses que, junto con los adelantados de la aljama, firmaron un acuerdo con las autoridades cristianas de la ciudad ". Obsérvese que en ese momento, es decir, 30 años antes de la fecha en que se acabó de copiar el manuscrito que ha dado origen al presente artículo, este Vidal ça-Torre (de quien aparte del nombre por ahora nada más sabemos) vivía en Lérida y no en Cervera.

${ }^{7}$ M. Beit-Arié y C. Sirat: Manuscrits médiévaux; pero recuerdan que Freimann (citado en nuestra nota 4) propuso leer Sartori.

${ }^{8}$ A. DurÁn y SANPERe, Referencies documentals del call de juhtus de Cervera. Discursos llegits en la «Real Academia de Buenas Letras» de Barcelona, Barcelona 1924, 68 págs. y A. DURAN I SANPERE, Documents aljamiats de jueus catalans, "Butlletí de la Biblioteca de Catalunya" V (1918-1919) 132-148, 5 láms. (separata: Barcelona 1920, 19 págs.). Estos dos artículos, pero prescindiendo de parte de los apéndices documentales, están reproducidos en A. DURAN I SANPERE, Llibre de Cervera, Barcelona 1977, págs. 345-390.

9 F. BAER, Die Juden im christlichen Spanien. Urkunden und Regesten, 2 vols., Berlin 1929-1936 (reimpresión Greg, England 1970); en adelante, BAER, JCS.

10 M. Canela I Garayoa y M. Turull I Rubinat, Tres pergamins inedits del segle $X I V$, "Butlletí de Dialectologia Nord-Occidental» IV (1985) 35-43. Edición de tres pergaminos el tercero de ellos (año 1369) sobre traslado de judíos dentro de la población. J. M. LlOBET PORTEllA, Los conversos según la documentación local de Cervera (1338-1501), «Espacio, Tiempo y Forma» 4 (= Homenaje al Profesor Eloy Benito Ruano, 1989) 335-350.

"F. BAER, JCS I, pág. 345. 
Dos años después de acabada la copia, es decir, en 1385 se construyó en Cervera una nueva sinagoga. Se conserva la lista de los judíos que compraron los asientos: uno de ellos fue "Vidal Saul, de Montblanch» ${ }^{12}$. Obsérvese, otra vez, que tampoco en este caso es un judío cervariense, sino (¿oriundo?) de Montblanc, localidad a 35 km al sur de Cervera. Excepto el nombre y el lugar de procedencia, sólo hay un dato que podría ser significativo: que en la misma sinagoga compró tres asientos Astruc Içach Adret, es decir, la persona para quien fue copiada la Biblia que nos ocupa.

En el estado actual de la investigación nada permite asegurar que esos dos judíos, Vidal ça-Torre y Vidal Saúl de Montblanch, sean una misma persona, y solamente una coincidencia permite suponer con cierta vaga probabilidad que Vidal Saúl pueda identificarse con el copista Vidal ben Saúl Satorre.

Por otra parte, quizá no sea inútil señalar que hay datos de otras personas del mismo apellido Satorre, aunque con distinto prenombre, pero en épocas o/y lugares muy alejados ${ }^{13}$.

\section{Vidal SaUl SatorRe en Zaragoza (1389-1411)}

En cambio, sí ha sido positivo el resultado en el caso de Zaragoza por el hecho de que uno de nosotros ha trabajado largos años en la documentación de los archivos zaragozanos. Pero vayamos lentamente.

En el colofón del manuscrito de París el copista Hayyim b. R. Saul Migdolí, llamado Vidal Satorre, explica que acabó de escribir esa Biblia para Isshaq hijo del honrado experto R. Yěhudâ ben Dina -isea su fin bueno!- en Zaragoza, en el mes de šĕbat del año 5164, que correspondería al período 14.1 a 12.2.1404, y explica que entonces tenía sesenta años y debía trabajar con la ayuda de lentes.

12 A. Durán y SANPere, Referencies documentals, pág. 37 = Llibre de Cervera, pág. 369, uno y otro citados en nuestra nota 8.

13 Mestre Abram Astruc ça Torre, Montblanc 1353 (Archivo del Real Patrimonio, registro 334, fol. 13v-2).- Bonanat ça-Torre, Tamarite 1421 (BAER, JCS I, n 529).Un Šlomó Satorre firma una suscripción en hebreo, Cervera 1436 (A. DURÁN I SANPERE y M. SchwAB, Les juifs d Cervera et dans d autres villes catalanes, "Sefarad" XXXIV (1974) pág. 110).- Salamó Catorre, Cervera 1454 (DuRAN y SAMPERE, Referencies documentals, pág. $25=$ Llibre de Cervera, pág. 358. Salamo çaTorra, Cervera 1467-1475 (BAER, JCS I, pág. 879). Vidal Astori, platero de Murviedro, años 14671469 (BAER, JCS II, pág. 340) y presente en Valladolid en 1476 (BAER, JCS II, $n^{2} 329$ ). 
El 30 de noviembre de 1389 se detecta por vez primera la presencia en Zaragoza de un judío llamado Vidal Saúl: comparece como testigo de Açach Feduchal en un documento de préstamo concedido por éste a unos musulmanes domiciliados en esa ciudad ${ }^{14}$. Un mes más tarde, un judío llamado Vidal Çatorre testifica la carta de deudo que Orovida de la Caballería, viuda del difunto Vidal de la Caballería ${ }^{15}$, concede a Hamet el Morisco e Ibrahim de la Morisca, habitantes en esa misma ciudad ${ }^{16}$. En ninguna de las dos ocasiones se especifica el lugar de residencia habitual del testigo judío.

Hasta ese momento, ni el nombre "Vidal Saúl" ni el apellido "Çatorre" habían aparecido registrados en los documentos notariales de Zaragoza ${ }^{17}$. Aunque en un principio todo parecía indicar que se trataba de dos personas diferentes, la información contenida en el colofón de la Biblia de Rašbá ${ }^{18}$, y, sobre todo, la mención de un judío llamado Vidal Saúl Çatorre en algunos documentos notariales de Zaragoza de finales del siglo XIV y comienzos del siglo XV ${ }^{19}$, permiten afirmar que ambas denominaciones se refieren a un mismo individuo, máxime si tenemos en cuenta que en esos años no debía de haber en esa ciudad otros judíos que respondieran a los nombres de Vidal Saúl o Vidal Çatorre, pues en tal caso se les habría adjudicado algún adjetivo diferenciador (mayor, menor, hijo de, etc.), según costumbre. Cualquier reticencia sobre la posibilidad de identificar al Vidal Saúl Çatorre, documentado en Zaragoza entre 1389 y 1411, con el autor de la Biblia de Rašbá y del manuscrito conservado en la Biblioteca Nacional de París, descrito por BeitArié y Sirat ${ }^{20}$, desaparece si tenemos en cuenta, además, que el

14 Archivo Histórico de Protocolos de Zaragoza (en adelante, AHPZ), Juan Blasco de Azuara, 1389, fol. 584.

15 Fue tesorero del rey. Véase M. Serrano y Sanz, Origenes de la dominación espantola en América, T. I: "Los amigos y protectores aragoneses de Cristóbal Colón", Madrid 1918, págs. 182 y siguientes; y F. Vendrell Gallostra, Aportaciones documentales para el estudio de la familia Caballeria, «Sefarad» III (1943) págs. 121-125.

16 AHPZ, Domingo Martín de Aguilón, registro de 1390, fols. 46.

${ }^{17}$ Hemos revisado toda la documentación notarial del siglo XIV y parte de la del XV existente en la ciudad.

18 Indica que el escriba fue "Vidal ben Saul Stwry». Véase la traducción latina del catálogo de Sassoon.

19 AHPZ, Domingo Martín de Aguilón, 22.4.1398, fols. 53v-54; y Juan de Capilla, 11.6.1405 y 3.2.1411, fol. 31 .

${ }^{20}$ Véase nuestra nota 7. 
personaje mencionado en la documentación de Zaragoza con los nombres de Vidal Çatorre/Vidal Saúl era librero ${ }^{21}$.

La multiplicidad de nombres registrada en los trece documentos notariales relacionados con Vidal Saúl/Vidal Çatorre/Vidal Saúl Çatorre resulta incomprensible en el caso de judíos zaragozanos ${ }^{22}$, pero se justifica plenamente si atendemos al origen leridano del individuo en cuestión ${ }^{23}$. En general, se observa que la frecuencia de la forma catalana ${ }^{24}$ es netamente superior a la aragonesa ${ }^{25}$ y a la que podríamos denominar mixta ${ }^{26}$, seguramente porque, aunque iba contra la costumbre de Aragón, era la preferida de la persona que estudiamos ${ }^{27}$.

No sabemos cómo ni cuándo llegó nuestro hombre a Zaragoza: es posible que se afincara en la ciudad en torno al año 1389 o incluso antes, aunque tampoco tenemos elementos de juicio suficientes para descartar que, tras una breve (¿o larga?) estancia en la capital de Aragón en torno al año 1389, se estableciera definitivamente allí a raíz de los acontecimientos de 1391 que, al parecer, se dejaron sentir en Cervera y su comarca ${ }^{28}$. En cambio, Zaragoza no sólo se libró de los ataques emprendidos contra las juderías sino

${ }^{21}$ El 18 de mayo de 1395 Vidal Çatorre, «livrerow, judío de Zaragoza, tenía 75 sueldos jaqueses en comanda de Pero Ferrer, vecino de dicha ciudad (AHPZ, Juan Blasco de Azuara, 18.5.1395, fol. 310v). Diez años después, Vidal Saúl, judío «livrero» habitante en Zaragoza, testificaba sendos documentos otorgados por el jubonero Abraham Moriel y por el sastre Salomón Horabuena (AHPZ, Juan de Capilla, 16.11.1405, s. f.).

${ }^{22}$ En Zaragoza, como en el resto de Aragón, los judíos reciben, además del nombre propio, el gentilicio o apellido.

${ }^{23}$ Véase nuestra nota 3.

24 La denominación Vidal Saúl aparece en siete documentos.

${ }^{25}$ El nombre de Vidal Çatorre se le aplica en tres ocasiones.

${ }^{26}$ Se le designa Vidal Saúl Çatorre tres veces.

${ }^{27}$ Quizás por eso, en un documento del 22 de abril de 1398 se observa lo siguiente: aunque inicialmente el notario Domingo Martín de Aguilón al reseñar el nombre de los testigos había escrito "Vidal Çatorre, judio de Çaragoça", posteriormente había intercalado el patronímico "Sahul» entre "Vidal» y "Çatorre" (AHPZ, Domingo Martín de Aguilón, 1398, fols. 53v-54).

${ }^{28}$ Fueron varios los judíos de esa zona que se trasladaron a Zaragoza en busca de nuevos horizontes: por ejemplo, Içach de Querçi, que en 1397 es denominado «jodio de Cervera habitant en Çaragoça" (AHPZ, Pedro de Carlos, 23.12.1397, fol. 368) mientras que en 1404 aparece registrado como «Açach de Carçi, jodio de Cervera d.Urgel» (AHPZ, Vicente Rodiella, 1.1.1404, fol. 4); y también rabí Nazanel (AHPZ, Domingo Martín de Aguilón, 9.12.1395, fols. 254v-255). 
que en los años sucesivos pasó a ser adalid del judaísmo de la Corona de Aragón ${ }^{29}$.

A comienzos del mes de noviembre de 1391 Vidal Saúl/Çatorre había fijado su domicilio en Zaragoza: sólo así se explica su participación activa en una asamblea de judíos pecheros reunida en ese año para resolver la emisión de un censal de 6.000 sueldos ${ }^{30}$. En 1395 Vidal Saúl se ganaba la vida como «livrero» ${ }^{31}$, oficio poco documentado entre los miembros de la judería zaragozana ${ }^{32}$ y que él seguía desempeñando diez años después ${ }^{33}$. En 1397 volvía a hacer acto de presencia en una reunión plenaria de la aljama, convocada con el fin de conseguir fondos para sufragar el pleito que la comunidad zaragozana sostenía contra los judíos Alazares ${ }^{34}$.

Aunque la información que tenemos sobre este personaje es escasa, sabemos que entre 1398 y 1411 fue testigo de diversos actos realizados ante notarios, cristianos ${ }^{35} \mathrm{y}$ judíos ${ }^{36}$. Las últimas noticias

29 A. Blasco Martínez, Los judíos en Aragón durante la Baja Edad Media, "Destierros Aragoneses. I: Judíos y moriscos", Zaragoza 1988, págs. 43-44.

30 AHPZ, Domingo Martín de Aguilón, 13.11.1391, fols. 223v-224.

${ }^{31}$ El 18 de mayo de 1395 Vidal Çatorre, "livrero", judío de Zaragoza, tiene 75 sueldos jaqueses en comanda de Pero Ferrer (AHPZ, Juan Blasco de Azuara, 1395, fol. 310v).

${ }^{32}$ Durante el siglo XIV y comienzos del XV Vidal Saúl es el único judío «librero» documentado en Zaragoza. Sus contemporáneos, los zaragozanos Mossé Deulocrega y Salomón Moheb, también estaban relacionados con el mundo del libro, pero realizaban otros menesteres: mientras que el primero de ellos era «maestro de ligar libros", el segundo destacaba como corredor de libros. Véase A. BLASCo MARTINEZ, Los judios de Zaragoza en el siglo XIV (tesis doctoral inédita, Zaragoza 1987), vol. VI, $\$ 8$ 6.2.1.5.2 y 6.2.3.3.5.

${ }^{33}$ AHPZ, Juan de Capilla, 1405.XI.16.

34 AHPZ, Jimeno de Alberuela, 1397, fol. 58v.

35 Además de los documentos ya citados (véase la nota 27), testificó una cesión de crédito realizada el 15 de marzo de 1402 por Açach Amato (AHPZ, Domingo Martín de Aguilón, fols. 36-36v), el compromiso arbitral contraído el 11 de junio de 1405 entre Benvenist de la Caballería y Ezdra Alazar, hijo de don Jucé (AHPZ, Juan de Capilla, 11.6.1405), la obligación adquirida el 16 de noviembre de 1405 por Abraham Moriel (AHPZ, Juan de Capilla, 16.11.1405) y el juramento pronunciado ese mismo día por Salomón Horabuena, comprometiéndose a no ausentarse de Zaragoza hasta saldar la deuda contraída con Juan de Pamies (AHPZ, Juan de Capilla, 16.11.1405).

${ }^{36}$ El 3 de marzo de 1411 Bonafós de la Caballería cede a Jento Feduchal, judío de Pina, hijo de Azmel, los 500 sueldos jaqueses que le eran debidos por Salomón Trigo, hijo de Abraham, según consta en carta uscripta de letra judayca el primero dia de janero, anyo de mil CCCC nueu al conto de los christianos, que yes de XIV dias de Tevet, anyo de V mil CLXIX al creamiento del mundo, por rabi Abraham de Salins et Vidal Saul Çatorre» (AHPZ, Juan de Capilla, 1411, fol. 31). 
registradas en Zaragoza acerca de Vidal Saúl son: un contrato del 2 de marzo de 1410, por el que Jaime Villanueva y su mujer Marquesa Terrén, de Zaragoza, se comprometen a entregarle los seis florines que le adeudan, sin ningún tipo de interés, el día de Navidad ${ }^{37}$; la carta a la que hemos hecho alusión ${ }^{38}$, y el pago de 500 sueldos jaqueses librados por la aljama de judíos de Zaragoza el 18 de febrero de 1411 a favor de Pedro Díaz Garlón, escudero de la casa del Arzobispo de esa ciudad, que fue testificado por el mencionado Vidal ${ }^{39}$.

Es muy probable que cierto Aarón Çatorre, domiciliado en Zaragoza en 1399 , fuese pariente suyo ${ }^{40}$. Pero nada podemos añadir al respecto pues, hasta la fecha, en las actas notariales zaragozanas de comienzos del siglo XV no hemos encontrado más noticias sobre el citado individuo.

En cuanto al destinatario del manuscrito realizado en 1404 por Vidal Saúl Çatorre, aunque en el colofón se indica que era Işbaq, hijo del honrado rabí Yěhudá ben Dina, consideramos oportuno señalar que en la documentación zaragozana de finales del siglo XIV y comienzos del $\mathrm{XV}$ no aparece registrado ningún judío con ese nombre de familia. Sin embargo, sí existe un grupo que se conoce por "Abendino" y cuyo principal representante en Zaragoza al filo de los siglos XIV-XV es Mossé Abendino, hombre de negocios, prestador y consejero de la aljama ". Desconocemos la filiación de este individuo, que seguramente se había trasladado a Zaragoza desde Belchite, villa próxìma a la capital ${ }^{42}$ en la que seguían residiendo sus hermanos Açach y Azmel ${ }^{43}$. Es posible que este Işbaq fuera el destinatario de la Biblia copiada por Vidal Saúl. Sabemos

${ }^{37}$ AHPZ, Domingo Martín de Aguilón, 2.3.1410, fols. 54v-55.

${ }^{38}$ Véase nuestra nota 36.

${ }^{39}$ AHPZ, Juan de Capilla, 18.2.1411, fol. 56v.

40 AHPZ, Juan Doto, 1399, protocolo, fol. 105 y registro, fol. 103.

4 A. Blasco Martinez, Los judios de Zaragoza (citado en nuestra nota 32).

42 La distancia entre Zaragoza y Belchite es de $49 \mathrm{~km}$.

${ }^{43}$ El 15 de julio de 1389 Bartolomé de Biu y Berenguer de Siscar, habitantes en Zaragoza, que junto con Samuel Cides, judío de Belchite, son arrendatarios de las rentas pertenecientes a la Reina "en la partida susana de Belchite», ceden sus derechos sobre el citado arrendamiento, para lo que queda de año, a Azmel Abendino y a Açach Abendino, judíos de Belchite ausentes de Zaragoza, y a su hermano Mossé Abendino, judío de esa ciudad, presente en el acto (AHPZ, Pedro Sánchez de Biel, 1389). 
que, aunque siguió domiciliado en Belchite, desde finales del siglo XIV Açach Abendino intervino en diversos negocios escriturados en Zaragoza ${ }^{44}$, y nos consta que en 1426 había alcanzado la madurez, pues se le aplicaba el calificativo de "mayor" ${ }^{45}$.

\section{RESUMEN}

Datos biográficos del copista Vidal Saúl Satorre = Hayyim Migdolí, que copió al menos dos Biblias en hebreo, fechadas en Cervera (1383) y en Zaragoza (1404). Gracias a la investigación archivística se le documenta esporádicamente en Lérida (1353) y Cervera (1385), y con bastante frecuencia en Zaragoza durante dos décadas (1389-1411), durante las cuales se le menciona con los diferentes nombres o grafias de Vidal Satorre, Vidal Saúl y Vidal Saúl Satorre. A pesar de su concisión, estas noticias revisten gran interés, más que para la personalidad artística del personaje, porque son muy escasos los documentos de archivo relacionados con copistas de manuscritos hebreos en la Edad Media.

\section{SUMMARY}

This paper contains biographical data of the copyist Vidal Saúl Satorre = Hayyim Migdolí, who copied at least two Bibles in Hebrew, which were dated at Cervera (1383) and Zaragoza (1404). Thanks to a thorough investigation through the archives, documentary evidence was produced which mentioned him as sporadically staying in Lérida (1353) and Cervera (1385), and rather more frequently, in Zaragoza in the course of two decades (1389-1411) during which he was referred to with the different names or spellings of Vidal Satorre, Vidal Saúl and Vidal Saúl Satorre. In spite of its conciseness, this information is of great interest due to the scarcity of the archival documents related to the copyists of Hebrew manuscripts in the Middle Ages, rather than to the knowledge of the artistic personality of that man.

${ }^{44}$ AHPZ, Domingo Martín de Aguilón, 1398, fols. 7v, 9v, 64 y 162v-163; y Juan Doto, 1405, fol. 211.

4s AHPZ, Antón Melero, 26.4.1426. 